\title{
Erratum
}

\section{Assessment of the Relative Safety of the Beta-Blockers ICI 141, 292 and Atenolol in Patients with Bronchial Asthma}

\author{
S. Groth, P.Tønnesen, M. Asted, H. Dirksen, P.G. Sørensen
}

Department of Clinical Physiology, The Finsen Institute and the Department of Lung Medicine, Lyngby Hospital, Copenhagen, Denmark

Eur J Clin Pharmacol (1986) 30:653-658

An unfortunate error occured in this article. The sentence: "The study has shown an almost change in lung function" should have been "The study has shown an almost identical change in lung function".

\section{Announcements}

Xth International Congress of Pharmacology (IUPHAR Sydney '87)

Sydney, Australia

23-28 August 1987

For further information contact:

The secretariat

Xth IUPHAR Congress

G. P.O. Box 2609

Sydney, NSW, Australia

Telephone: $(+61)(02) 2411478$

Telex: AA 74845 CONSEC

Cables: CONVENTION Sydney
III. International Conference on Drug Absorption

The Third International Conference on Drug Absorption will be held in Edinburgh from

September 28-30, 1988

Further information is available from:

Dr. Ian Sword

Inveresk Research International Ltd.

Musselburgh EH21 7UB, Scotland

Tel.: 0316656881

Telefax: 0316659976

Telex: 727228 